\title{
Functionality Testing of Water Pressure and Flow Calculation for Dynamic Power Plant Modelling
}

\author{
Timo Yli-Fossi \\ Department of Automation Science and Engineering, Tampere University of Technology, Finland
}

\begin{abstract}
Water pressure and flow rate calculation in dynamic boiler models is challenging because of stiff system dynamics meaning that time constants of model states vary by several orders of magnitude. Furthermore, strong interconnections between pressures and flow variables may cause instability problems in simulation runs. This study presents a method to implement and test dynamic thermal power plant water-steam system models. A dynamic water-steam system model is presented. The model is applied for testing of the functionality of the presented computation model. Computational performance was tested using different numerical solvers. Also sensitivity to changes in initial values of system states and model parameters was tested. The results indicate that a workable way to make flexible models was found.
\end{abstract}

Keywords: modelling, simulation, power plant

\section{Introduction}

Water is the working fluid of steam power plants. Different physical phases of water set challenges to modelling work. Process components can contain subsaturated liquid, saturated liquid-vapour mixture and superheated steam. In supercritical boilers supercritical fluid is also present. Physical characteristics of water, such as density and vapour fraction, change as functions of fluid pressure and enthalpy. Water properties affect also to pressure losses and heat transfer coefficients between the fluid and the internal surfaces of the process components. Temperature differences and flow rates affect heat flows. Likewise pressures and flows are dependent on each other. Therefore, the strong interconnections between the variables, nonlinearity and time variant phenomena set challenges to the modelling and simulation work.

Mathematically, dynamic pressure and flow models are stiff systems of differential equations. Generally, stiffness can be described as a property that existing time constants of the system states differs from each other by several orders of magnitude. A basic difficulty in numerical solutions of stiff models is a requirement of absolute stability. Numerical problems may result to noise in simulation results, which further may lead simulation run to fail. ( $\AA$ man, 2011)

Besides the stiffness, computational problems are caused by calculation errors and discontinuities. Truncation and rounding errors are caused by digital computing. The truncation error forms a difference between the numerical and real solution. The rounding error results from limited calculation accuracy. Extension of the simulation step length will expand the truncation error but reduce the rounding error when the amount of calculation operations is reduced. If the time step has been selected too long, the solution may begin to oscillate and calculated values to drift away from an allowed area. (Jäntti, 1996)

The differential and/or partial differential equations of the dynamic models can be non-linear, contain discontinuities and consist of complex boundary conditions. Hence, numerical solvers must be applied in simulations. The choice of the solver has significance for simulation speed and accuracy. Numerical methods are often classified in two groups: explicit and implicit. Explicit methods calculate the next state of a model from the current state. Implicit methods find a solution by solving equations involving both the current state and the next one. Implicit methods are usually more efficient when solving stiff models. Implicit methods require an extra computation, but on the other hand the time step to be used can often be lengthened so that the stability of the solution does not suffer. (Åman, 2011; Jäntti, 1996)

Solvers can also be divided into two main types: fixedstep and variable-step solvers. The solvers, which use the variable step, adjust the step length according to the situation. During a fast transient situation, a minor step size is required in the integration. When the model has slow dynamics, near steady state situation and the changes are small, the use of the longer time step is reasonable.

Special situations such as small flows or quick pressure changes may also cause computational problems. The pressure and flow models may also be sensitive to initial values of state and model parameters. This complicates the revision of the models. 
Instabilities in modelled pressure and flow, which are not caused by computational reasons, may also be found. This brings the extra challenge for the examination of the instabilities of the model. For example, oscillations can cause problems in control system, boiling crisis and excursion of flow due to differences in the pressure drop characteristics of different flow pattern. Pressure and flow instabilities exist especially during startups and shutdowns. (Majuri, 2012)

The objective of this study was to find the workable way to implement reliable and stable models. The models must be also flexible and easily edited. The water pressure and flow model has been developed for functionality testing. Additionally, the sensitivity of the model has been tested in different ways.

\section{Modelling}

The water-steam system of the thermal power plant consists of several process components. System models can be built by combining model blocks of these subsystems. In this work, the blocks can be classified as follows: pressure and flow values are calculated in the pressure point model blocks, and pressure rise and drop and heat transfer are modelled in the pump, valve and process element/heat exchanger model blocks.

\subsection{Basic Process Components}

Figure 1 presents a simple example of a process model, which contains two pressure points, a pump, valve and a process element. The water pressure and the outgoing flow are calculated in the point. Pump and valve models calculate pressure rise $\Delta p_{\text {pump }}[\mathrm{Pa}]$ and drop $\Delta p_{\text {valve }}$ $[\mathrm{Pa}]$, respectively. Pressure rise is a function of the pump speed. Pressure drop between pressure points can be controlled by manipulating the valve stem position. In the literature there are several different equations to the pressure and flow calculation of pumps and valves (Kirmanen et al., 2012; Ordys et al., 1994). The input variables of all model blocks are mass flow, inlet pressure and inlet enthalpy of water. Similarly, the outputs are mass flow, outlet pressure and outlet enthalpy. Parameters of blocks can be determined based on the dimensions of the component and other properties.

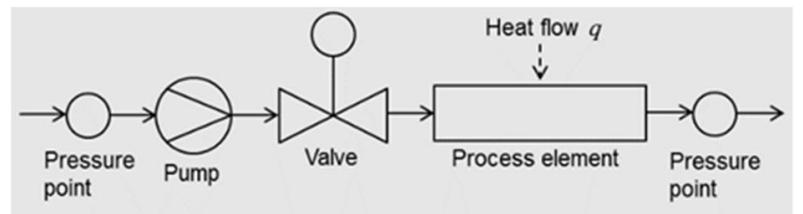

Figure 1. An example of a structure of the pressure and flow model.

Process element model block represents different watersteam side components such evaporators, superheaters, economisers and pipes. It is also possible to divide the modelled sub-processes into several model blocks because the model blocks can be connected together. The element model block contains calculations of pressure drop $\Delta p_{\text {elem }}[\mathrm{Pa}]$ according to (Pioro et al., 2004)

$$
\Delta p_{\text {elem }}=\Delta p_{\text {fric }}+\Delta p_{\text {loc }}+\Delta p_{\text {acc }}+\Delta p_{\text {elev }}
$$

where $\Delta p_{\text {fric }}, \Delta p_{\text {loc }}, \Delta p_{\text {acc }}$ and $\Delta p_{\text {elev }}$ are the pressure drops $[\mathrm{Pa}]$ due to frictional resistance, local flow obstruction, acceleration of flow and gravity. There are several equations in literature, which can be applied to pressure drop calculation. (Pioro et al., 2004; Tong and Tang, 1997)

The process element model block calculates also the time derivate of water enthalpy, which is affected by the enthalpy of inlet water flow and the heat transfer between water and walls of the process element. Moreover, the heat transfer and pressure drop depend on water properties and flow rate. The properties of water are interpolated from water-steam tables. The block is able to handle the thermodynamics of liquid water, saturated water-steam mixture, superheated steam, and supercritical fluid. The model block selects suitable water side heat transfer coefficient and pressure drop for different situations. The model block includes also metal walls (and possible refractory layers) of represented process components. Also the conductive heat transfer through these walls and layers has been modelled. The model block calculates time derivatives of metal and refractory walls temperatures. (Yli-Fossi et al., 2011; Yli-Fossi et al., 2012)

Pressure point model block calculates time derivatives of pressure and outlet fluid mass flow(s). The calculation of pressure $p[\mathrm{~Pa}]$ for single-phase water and steam is based on the following equation ( $\mathrm{Lu}, 1999)$

$$
\frac{\mathrm{d} p}{\mathrm{~d} t}=-\frac{\left(w_{\mathrm{i}} h_{\mathrm{i}}-w_{\mathrm{o}} h_{\mathrm{o}}+q\right)-\left(\frac{\rho}{\frac{\partial \rho}{\partial h}}+h\right)\left(w_{\mathrm{i}}-w_{\mathrm{o}}\right)}{V\left(1+\frac{\rho \frac{\partial \rho}{\partial p}}{\frac{\partial \rho}{\partial h}}\right)}
$$

where $w_{\mathrm{i}}$ and $w_{\mathrm{o}}$ are inlet and outlet mass flow rates $[\mathrm{kg} / \mathrm{s}] . h_{\mathrm{i}}$ and $h_{\mathrm{o}}$ are inlet and outlet enthalpies $[\mathrm{J} / \mathrm{kg}] . q$ is heat flow $[\mathrm{J} / \mathrm{s}]$ to fluid. $\rho$ and $h$ are density $\left[\mathrm{kg} / \mathrm{m}^{3}\right]$ and enthalpy in a control volume $V\left[\mathrm{~m}^{3}\right]$. A certain part of the modelled process can be defined as the control volume. 
The time derivative of pressure for two-phase liquid and vapour mixture can be calculated as (Lu, 1999)

$$
\begin{gathered}
\frac{\mathrm{d} p}{\mathrm{~d} t}=\frac{\left(w_{\mathrm{i}} h_{\mathrm{i}}-w_{\mathrm{o}} h_{\mathrm{o}}+q\right)-\frac{\rho_{\mathrm{l}} h_{\mathrm{l}}-\rho_{\mathrm{v}} h_{\mathrm{v}}}{\rho_{\mathrm{l}}-\rho_{\mathrm{v}}}\left(w_{\mathrm{i}}-w_{\mathrm{o}}\right)}{e_{\mathrm{l}} V_{\mathrm{l}}+\mathrm{e}_{\mathrm{v}} V_{\mathrm{v}}} \\
e_{1}=\rho_{\mathrm{l}} \frac{\partial h_{1}}{\partial p}+\frac{\rho_{\mathrm{v}}\left(h_{\mathrm{v}}-h_{\mathrm{l}}\right)}{\rho_{\mathrm{l}}-\rho_{\mathrm{v}}} \frac{\partial \rho_{\mathrm{l}}}{\partial p}-1 \\
e_{\mathrm{v}}=\rho_{\mathrm{v}} \frac{\partial v}{\partial p}+\frac{\rho_{\mathrm{l}}\left(h_{\mathrm{v}}-h_{\mathrm{l}}\right)}{\rho_{\mathrm{l}}-\rho_{\mathrm{v}}} \frac{\partial \rho_{\mathrm{v}}}{\partial p}-1
\end{gathered}
$$

where $\rho_{\mathrm{l}}$ and $\rho_{\mathrm{v}}$ are liquid and vapour densities $\left[\mathrm{kg} / \mathrm{m}^{3}\right]$ and $h_{1}$ and $h_{\mathrm{v}}$ are liquid and vapour enthalpies [J/kg] in the control volume $V\left[\mathrm{~m}^{3}\right]$.

The time derivative of liquid volume $V_{1}\left[\mathrm{~m}^{3}\right]$ in the control volume can be expressed as ( $\mathrm{Lu}, 1999)$

$$
\frac{\mathrm{d} V_{1}}{\mathrm{~d} t}=\frac{w_{\mathrm{i}}-w_{\mathrm{o}}-\left(V_{1} \frac{\partial \rho_{\mathrm{l}}}{\partial p}+V_{\mathrm{v}} \frac{\partial \rho_{\mathrm{v}}}{\partial p}\right) \frac{\mathrm{d} p}{\mathrm{~d} t}}{\rho_{\mathrm{l}}-\rho_{\mathrm{v}}}
$$

Vapour volume $V_{1}\left[\mathrm{~m}^{3}\right]$ in the control volume is $(\mathrm{Lu}$, 1999)

$$
V_{\mathrm{v}}=V-V_{\mathrm{l}}
$$

The time derivative of the outlet fluid mass flow $[\mathrm{kg} / \mathrm{s}]$ from the pressure point model block is calculated as (Fabian, 2009)

$$
\frac{\mathrm{d} w}{\mathrm{~d} t}=\frac{p-p_{\text {next }}-\Delta p_{\text {tot }}}{L / A}
$$

where $p$ is pressure $[\mathrm{Pa}]$ in the pressure point and $p_{\text {next }}$ is pressure $[\mathrm{Pa}]$ in the next pressure point in the flow direction. According to Figure 1, $p$ is the pressure of the left pressure point model block and $p_{\text {next }}$ is the pressure of the right point. $L$ and $A$ are the total length [m] and inner cross-sectional areas $\left[\mathrm{m}^{2}\right]$ of tubes of process components between pressure point model blocks for $p$ and $p_{\text {next }}$. Fluid inertia $L / A$ is most significant in long and slender tubes. $\Delta p_{\text {tot }}[\mathrm{Pa}]$ is the total pressure drop between the pressure points. In case of Figure 1, $\Delta p_{\text {tot }}$ can be determined as

$$
p_{\text {tot }}=\Delta p_{\text {pump }}+\Delta p_{\text {valve }}+\Delta p_{\text {elem }}
$$

In literature there are alternative ways to calculate mass flows (Jäntti, 1996; Lu, 1999). In this work the Equation 6 , based on Newton's second law, is applied. The same equation is used for liquid water and vapour. The compressibility of vapour is considered in the pressure equations.

\subsection{Boiler Evaporator Loop}

Steam boilers can be classified according to the structures of the evaporation process. The types are drum boilers with natural or forced circulation, and a once-through design. Boiling occurs in evaporator tubes which form furnace walls. Figure 2 illustrates the structure of the forced circulation system. The main components of the system are: the steam drum, downcomer pipes, circulation pump and riser tubes. The drum separates steam from the saturated watersteam mixture flowing out from the riser tubes. Downcomer pipes convey water from the drum to the lowest part of the evaporator under the furnace floor. Riser tubes lead water back from the bottom of the furnace to the drum. The outlet flow from the riser tubes consist of saturated water and saturated steam, which are separated from each other in the steam drum. Saturated water mixed with new feed water is circulated back from the drum to the evaporator and saturated steam is led to the superheaters to be heated up. In a natural circulation boiler, the density difference between liquid water in downcomer and water-steam mixture in riser provides the pressure difference required for circulation. In a forced circulation boiler, a pump is used to increase the circulation rate as compared to that of a natural circulation boiler. (Åström and Bell, 2000; Li et al., 2005)

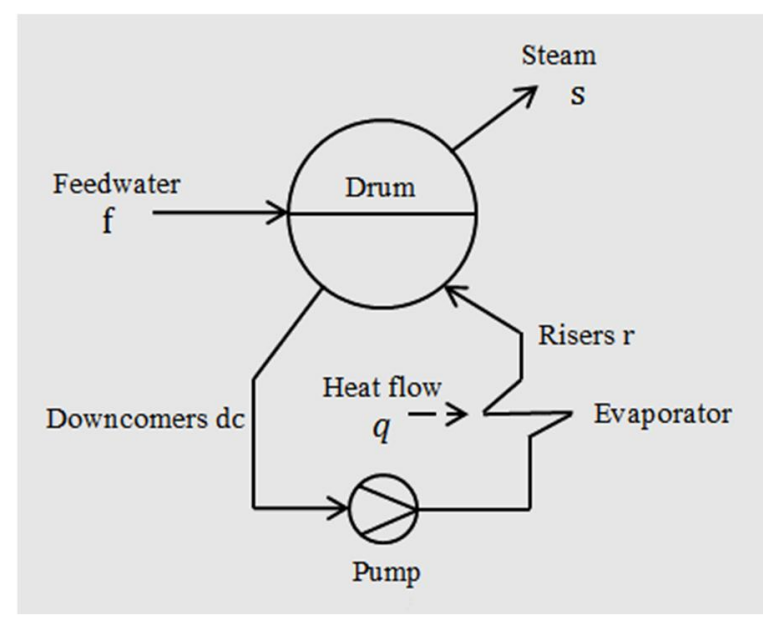

Figure 2. The structure of the circulating evaporation system.

Several studies about the modelling of the circulating evaporation process can be found in the literature. In the presented model the drum pressure is determined as (Åström and Bell, 2000) 


$$
\begin{gathered}
\frac{\mathrm{d} p}{\mathrm{~d} t}= \\
\frac{\left(w_{\mathrm{f}} h_{\mathrm{f}}-w_{\mathrm{s}} h_{\mathrm{s}}+q\right)-\left(\rho_{\mathrm{l}} h_{\mathrm{l}}-\rho_{\mathrm{v}} h_{\mathrm{v}}\right) \frac{\mathrm{d} V_{\mathrm{lt}}}{\mathrm{d} t}}{V_{\mathrm{lt}}\left(h_{\mathrm{l}} \frac{\partial \rho_{\mathrm{l}}}{\partial p}+\rho_{\mathrm{l}} \frac{\partial h_{\mathrm{l}}}{\partial p}\right)+V_{\mathrm{vt}}\left(h_{\mathrm{v}} \frac{\partial \rho_{\mathrm{v}}}{\partial p}+\rho_{\mathrm{v}} \frac{\partial h_{\mathrm{v}}}{\partial p}\right)-V_{\mathrm{t}}+m_{\mathrm{t}} C_{p} \frac{\partial T_{\mathrm{s}}}{\partial p}} \\
\frac{\mathrm{d} V_{\mathrm{lt}}}{\mathrm{d} t}=\frac{w_{\mathrm{f}}-w_{\mathrm{s}}-\left(V_{\mathrm{lt}} \frac{\partial \rho_{\mathrm{l}}}{\partial p}+V_{\mathrm{vt}} \frac{\partial \rho_{\mathrm{v}}}{\partial p}\right) \frac{\mathrm{d} p}{\mathrm{~d} t}}{\rho_{\mathrm{l}}-\rho_{\mathrm{v}}}
\end{gathered}
$$

where $w_{\mathrm{f}}$ and $w_{\mathrm{s}}$ are the mass flows $[\mathrm{kg} / \mathrm{s}]$ of the feed water to the drum and the steam flow from the drum. $h_{\mathrm{f}}$ and $h_{\mathrm{s}}$ are the enthalpies [J/kg] of the feedwater and the saturated steam. $\rho_{\mathrm{l}}$ and $\rho_{\mathrm{v}}$ are liquid and vapour densities $\left[\mathrm{kg} / \mathrm{m}^{3}\right]$ and $h_{\mathrm{l}}$ and $h_{\mathrm{v}}$ are liquid and vapour enthalpies $[\mathrm{J} / \mathrm{kg}]$ in the drum. $V_{\mathrm{lt}}$ and $V_{\mathrm{vt}}$ are liquid and steam volumes $\left[\mathrm{m}^{3}\right]$ in the total circulation evaporation system. $m_{\mathrm{t}}$ is the mass $[\mathrm{kg}]$ of the metal structure of the system. $C_{p}$ is the specific heat capacity $[\mathrm{J} /(\mathrm{K} * \mathrm{~kg})]$ of metal and $T_{\mathrm{s}}$ is the saturation temperature $[\mathrm{K}]$ of the steam.

The flow through the downcomers can be calculated as (Li et al., 2005)

$$
\frac{\mathrm{d} w_{\mathrm{dc}}}{\mathrm{d} t}=\frac{\rho_{\mathrm{dc}} g H_{\mathrm{dc}}-\int_{0}^{L_{\mathrm{r}}} \rho_{\mathrm{r}} g \mathrm{~d} z-\Delta p_{\mathrm{r}}-\Delta p_{\mathrm{dc}}+\Delta p_{\mathrm{pump}}}{\left(L_{\mathrm{dc}}+L_{\mathrm{r}}\right) / A_{\mathrm{dc}}}
$$

where $\rho_{\mathrm{dc}}$ and $\rho_{\mathrm{r}}$ are the densities $\left[\mathrm{kg} / \mathrm{m}^{3}\right]$ of the process fluid in the downcomers and the risers. $L_{\mathrm{dc}}$ and $L_{\mathrm{r}}$ are the the lengths $[\mathrm{m}]$ of of the downcomers and the risers. $H_{\mathrm{dc}}$ is the height [m] of the downcomers. $z$ is the vertical position [m] in the risers. $g$ is the gravitation constant $\left[\mathrm{m} / \mathrm{s}^{2}\right] . A_{\mathrm{dc}}$ is the inner cross-sectional area $\left[\mathrm{m}^{2}\right]$ of the risers. $\Delta p_{\mathrm{dc}}, \Delta p_{\mathrm{r}}$ and $\Delta p_{\text {pump }}$ are the pressure drops $[\mathrm{Pa}]$ across the downcomers, the risers and the circulation pump. $\Delta p_{\text {pump }}$ is omitted if a natural circulation boiler is modelled.

The flow through the risers can be presented as (Åström and Bell, 2000)

$$
\begin{gathered}
w_{\mathrm{r}}=w_{\mathrm{dc}}-V_{\mathrm{r}}\left(\alpha_{v} \frac{\partial \rho_{\mathrm{v}}}{\partial p}+\left(1-\alpha_{v} \frac{\partial \rho_{\mathrm{l}}}{\partial p}\right)\right. \\
\left.+\left(\rho_{\mathrm{l}}-\rho_{\mathrm{v}}\right) \frac{\partial \alpha_{v}}{\partial p}\right) \frac{\mathrm{d} p}{\mathrm{~d} t} \\
+\left(\rho_{\mathrm{l}}-\rho_{\mathrm{v}}\right) V_{\mathrm{r}} \frac{\partial \alpha_{v}}{\partial \alpha_{r}} \frac{\mathrm{d} \alpha_{r}}{\mathrm{~d} t}
\end{gathered}
$$

where $V_{\mathrm{r}}$ is the volume $\left[\mathrm{m}^{3}\right]$ of the risers. $\alpha_{v}$ is the average steam volume fraction. $\alpha_{r}$ is steam mass fraction at the risers' outlet.

Condensate and steam flow rates through the surface level in the drum can also be modelled by the equations found in the literature (Åström and Bell, 2000).

\subsection{Test Model}

This work is a part of the wider modelling work where different types of steam power plants have been modelled. These models include also the air-flue gas system and the dynamics of combustion and the heat transfer from hot flue gases to heat exchanger structures. Also the main control loops are included. The models can be used for several purposes, such as control design and process development. The focus of this paper is on the testing of pressure and flow calculations. A fairly simple model is used for the testing, because it facilitates the analysis of the computation and the examination of the functionality. The dynamic water-steam system model has been developed using Simulink and Matlab by The MathWorks Inc. The process is modelled as a continuous time model.

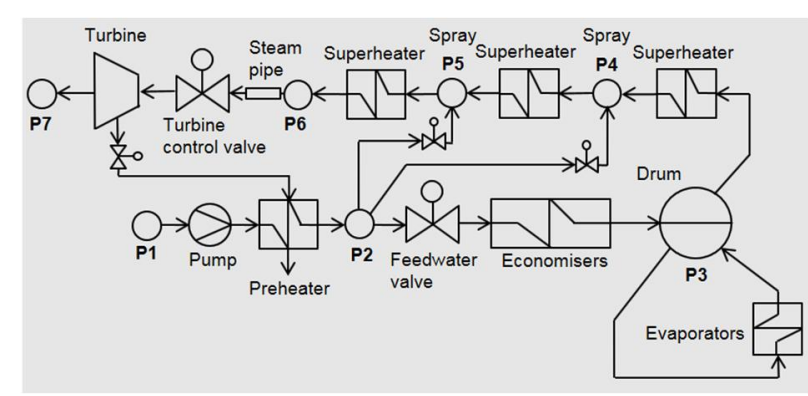

Figure 3. The diagram of the dynamic power plant watersteam system model.

Figure 3 illustrates the structure of the test model. The water-steam system model consists of a feedwater pump and a valve, a preheater, economisers, a drum, and a natural circulation evaporator, three superheaters, two attemperation sprays and a steam pipe, a turbine valve and a steam turbine. The flue gas side has not been included in this model. Suitable heat flows are only added to the model blocks of the economisers, the evaporators and the superheaters as input variables. Feed water is heated by the preheater taking heat energy from steam extracted from the steam turbine. The economisers (flue gas preheaters) increase feed water temperature after the preheaters near to the boiling point. The evaporators generate steam and the drum separates steam from saturated liquid-vapour mixture. The superheaters increase the live steam temperature before the turbine. Superheated steam temperature is controlled by attemperation sprays. The cooling water is taken before the feedwater valve. The spray valves are 
also modelled. The main pressure is controlled by the heat power directed to the evaporators. The turbine control valve is used to regulate the steam flow to the turbine. A drum level control is also implemented in the model. The level is adjusted with the feedwater flow. The controllers are needed to achieve the desired steady state of the system. The pressure point model blocks have been marked on Figure 3 with P1...P7. The presented equations are applied in each blocks.

\section{Simulation Tests}

The presented model has been tested in different ways. The numerical solvers were compared with test runs. The effect of the correctness of the initial values of the states has been studied. The tolerance of the model to the changes in the parameters and the structure was also examined.

\subsection{Comparison of Numerical Solvers}

The MATLAB offers several solvers for solving ordinary differential equations (ODEs). The ode45 solver was chosen as a reference solver which is more suitable for nonstiff systems. The ode45 solver uses a variable step and one-step Runge-Kutta procedure. It calculates both the fourth and fifth order approximations. The MATLAB/Simulink environment contains four solvers, ode $15 \mathrm{~s}$, ode $23 \mathrm{~s}$, ode $23 \mathrm{t}$ and ode23tb, all of which are designed to solve stiff equations. The numbers in the names represent the orders of the approximations. Ode15s solver turned out to be very slow for the test model and for this reason it was left out from the more exact study. The ode 15 is a multistep solver which is based on the numerical differentiation formulas. The one-step ode $23 \mathrm{~s}$ solver is based on a modified Rosenbrock formula of the second order. The ode $23 \mathrm{t}$ is an implementation of the trapezoidal rule using a free interpolation. The ode23tb is an implementation of TR-BDF2. (MATLAB: Documentation, 2016)

The comparative simulation test runs were performed by different solvers. Each solver was tested with three values, $1 \mathrm{e}-3,1 \mathrm{e}-5$ and $1 \mathrm{e}-8$, of the relative tolerance. The relative tolerance measures the error relative to the size of each state. The relative tolerance represents a percentage of the state's value. For example, value 1e-3, means that the computed state will be accurate to within $0.1 \%$. The parameter of the absolute tolerance was set in auto-mode. The same initial values of the states were set for each simulation run. The model was near steady state at full load. The lengths of the runs were 100 simulated seconds. The results of the simulation runs are summarized in Table 1. The speed is presented as a ratio between a real time and consumed simulation time. Decrement of the tolerance decreases simulation speed and noise of calculated variables. The solvers ode 45 and ode23s are clearly slower than the solvers ode23t and ode23tb. Figures 4 and 5 present simulated steam pressure and mass flow in the point P6 after the last superheater. Oscillations of the simulated results are distinctly seen especially when the relative tolerance is 1e-3. The solver is ode23tb, which seems the most efficient on the basis of Table 1 . In this case, it seems that the suitable compromise between simulation speed and accuracy is achieved with relative tolerance 1e-5.

Table 1. Comparison of the Solvers

\begin{tabular}{|c|c|c|c|c|}
\hline Name & $\begin{array}{l}\text { Relative } \\
\text { tolerance }\end{array}$ & $\begin{array}{l}\text { P6: } \\
\text { Pressure } \\
\text { deviation: } \\
\text { variance } \\
{[\%]}\end{array}$ & $\begin{array}{l}\text { P6: } \\
\text { Mass flow } \\
\text { deviation: } \\
\text { variance } \\
{[\%]}\end{array}$ & $\begin{array}{l}\text { Simulation } \\
\text { speed: } \\
\text { real time / } \\
\text { simulated } \\
\text { time }\end{array}$ \\
\hline \multirow{3}{*}{ ode 45} & $1 \mathrm{e}-3$ & $0.1075 \mathrm{e}-2$ & $1.1419 \mathrm{e}-2$ & 0.4463 \\
\hline & $1 \mathrm{e}-5$ & $0.0184 \mathrm{e}-2$ & $0.3303 \mathrm{e}-2$ & 0.4244 \\
\hline & $1 \mathrm{e}-8$ & $0.0185 \mathrm{e}-2$ & $0.3294 \mathrm{e}-2$ & 0.3497 \\
\hline ode15s & $1 e-3$ & not tested & not tested & very slow \\
\hline \multirow{3}{*}{ ode $23 \mathrm{~s}$} & $1 e-3$ & $0.0413 \mathrm{e}-2$ & $0.4899 \mathrm{e}-2$ & 0.5520 \\
\hline & $1 e-5$ & $0.0414 \mathrm{e}-2$ & $0.4905 \mathrm{e}-2$ & 0.5428 \\
\hline & $1 \mathrm{e}-8$ & $0.0324 \mathrm{e}-2$ & $0.4291 \mathrm{e}-2$ & 0.3042 \\
\hline \multirow{3}{*}{ ode $23 t$} & $1 e-3$ & $0.0261 \mathrm{e}-2$ & $0.3646 \mathrm{e}-2$ & 7.3868 \\
\hline & $1 e-5$ & $0.0223 \mathrm{e}-2$ & $0.3571 \mathrm{e}-2$ & 4.8860 \\
\hline & $1 \mathrm{e}-8$ & $0.0220 \mathrm{e}-2$ & $0.3545 \mathrm{e}-2$ & 1.0878 \\
\hline \multirow{3}{*}{ ode 23 tb } & $1 e-3$ & $0.7236 \mathrm{e}-2$ & $3.8129 \mathrm{e}-2$ & 8.3178 \\
\hline & $1 e-5$ & $0.0516 \mathrm{e}-2$ & $0.4356 \mathrm{e}-2$ & 8.1136 \\
\hline & $1 \mathrm{e}-8$ & $0.0222 \mathrm{e}-2$ & $0.3566 \mathrm{e}-2$ & 3.3905 \\
\hline
\end{tabular}
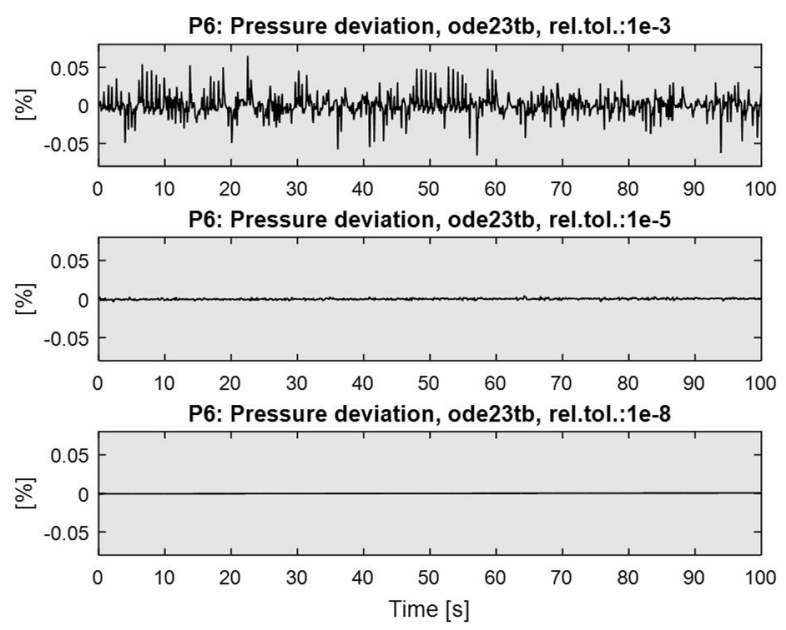

Figure 4. Simulated steam pressure in the point P6 using different values of the relative tolerance by the solver ode23tb. 

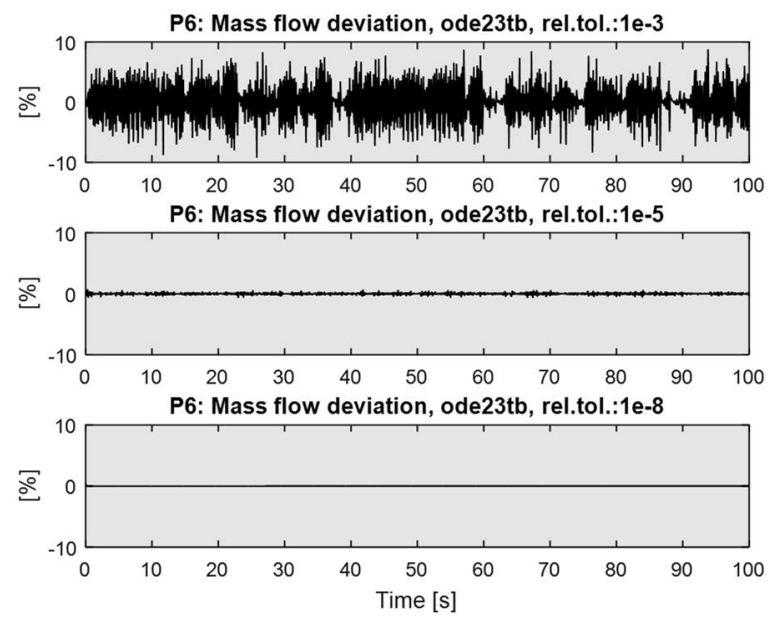

Figure 5. Simulated steam mass flow in the point P6 using different values of the relative tolerance by the solver ode $23 \mathrm{tb}$.

\subsection{Effects of Initial State and Parameters}

The initial values of the model state have high significance from the point of view of the functionality of the model. To setting the model first time to the steady state may be difficult. The correct initial values can be calculated or estimated before the first simulation run. However, this can be time-consuming and troublesome. The second alternative is to simulate the model to the desired state. The challenge is that wrong initial values can lead the simulation run to fail. In any case, when the desired state has been reached, it can be saved. Saved states can be used to the initialisation of the state values. The changing of the parameters and structure of the model may also cause problems. For this reason, it is a significant advantage if the model tolerates different state values and updating of the model.

Figure 6 represents a case where the initial values of the outlet pressure and outlet mass flow of the pressure point P5 were set incorrect in the full load state. The deviation of the outlet pressure was set $-15 \%$ and the outlet mass flow $-100 \%(0 \mathrm{~kg} / \mathrm{s})$ before a simulation run. Other model state variables were at the proper values. All controllers were set on manual mode. The figure proves that the model tolerates the false initial values and settles in steady state. However, if the deviation of the pressure was set $-20 \%$, then the simulation run failed.

The drum model functionality also was tested in the same way. The initial value of the drum pressure was set about $-15 \%$ smaller than in the full load situation. Figure 7 shows that the drum pressure began to rise immediately at the beginning of the simulation. The steam flow from the drum was decreased because the drum pressure was smaller than in the next pressure point P4. Steam flow returned normal when the drum pressure rose enough. Figure 8 presents the mass flows of the downcomers and the risers in the evaporation loop in the same simulation run. The pressure deviation affected the riser flow more strongly than into the dowcomer flow. At the end of the simulation the flows reached the balances. The model tolerated the change of the initial value of the drum pressure.
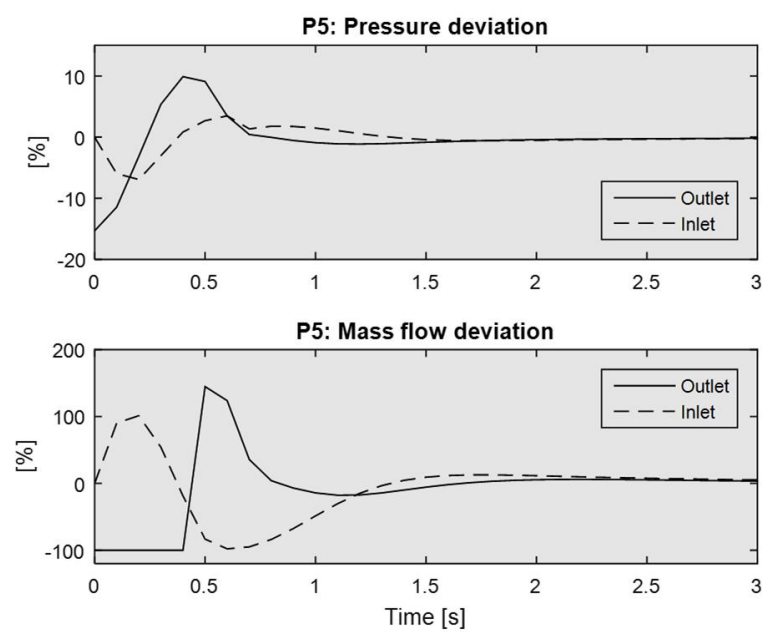

Figure 6. Simulated pressures and mass flows in the point P5.
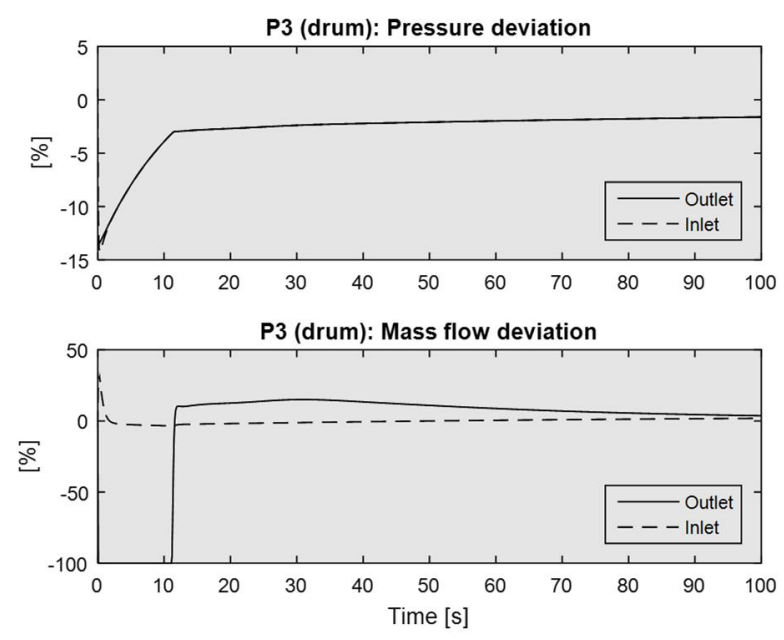

Figure 7. Simulated pressures and mass flows in the drum.

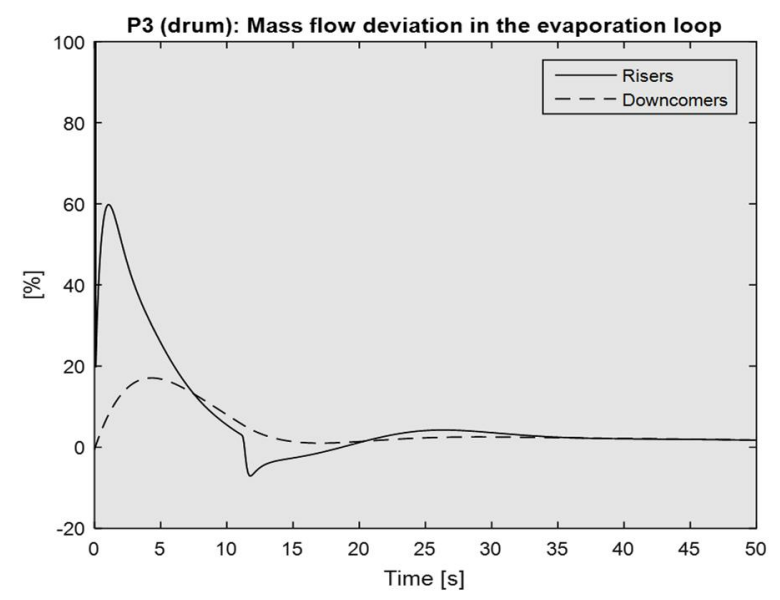

Figure 8. Simulated downcomer and riser mass flow in the drum. 
Effect of the changes in the model parameters was also tested by the model. It turned out that the model tolerated well a change in the size of the drum and other process components. Effect of the editing of the structure of the model also was studied. A new superheater model was added between the present superheater and the pressure point $\mathrm{P} 4$. Thus, the new model version contained two superheater model blocks between the drum and P4. The controllers were set to auto-mode in this simulation test. The adding of the model block caused oscillation before the model settled in the balance, which can be seen in Figure 9. The initial state of the new block was far from the reasonable values. For example, in the start situation the vapour mass fraction was zero inside the new superheater. In spite of this the model was able to handle the unconventional situation. The reasonable values were reached in the end of the simulation run.
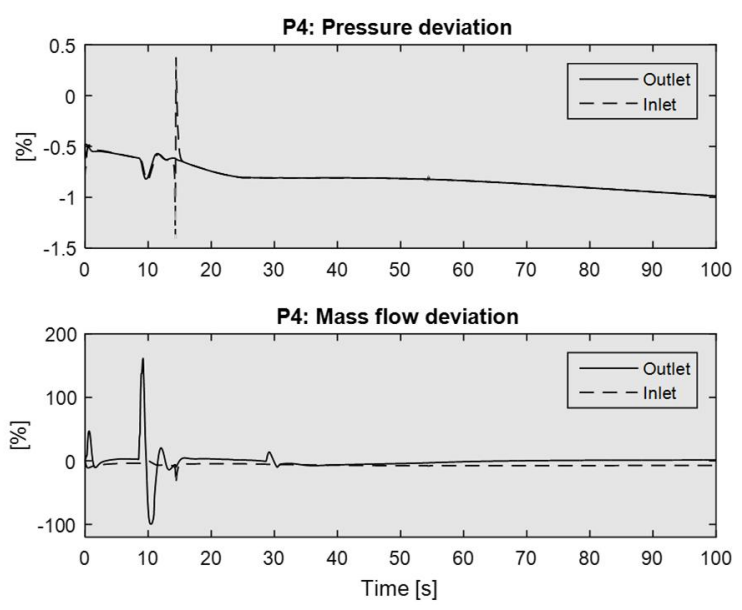

Figure 9. Simulated pressures and mass flows in the point P4.

\section{Conclusions}

A dynamic power plant water side model and selected water pressure and flow equations has been presented. The equations are based on physical equations. The suitable solver's choice was also studied and tested. Functionality testing proved that the model tolerates different changes well within certain limits. A workable way to make flexible models with pressure and flow calculation was found.

\section{Acknowledgements}

This work was carried out in the FLEXe research program coordinated by CLIC Innovation Ltd. The work has also funded Neles 30-year Anniversary Foundation. These supports are gratefully acknowledged.

\section{References}

B. Fabian, Analytical System Dynamics: Modeling and Simulation. Springer Science+Business Media, 2009.
T. Jäntti, Dynamic simulation of a circulating fluidized bed boiler. Master of Science Thesis, Lappeenranta University of Technology, 1996.

J. Kirmanen, I. Niemelä, J. Pyötsiä, M. Simula, M. Hauhia, J. Riihilahti, V. Lempinen, Koukkuluoma J. and P. Kanerva, Flow Control Manual. Metso Automation Inc., 6th Edition, 2011.

B. Li, T. Chen and D. Yang, DBSSP - A computer program for simulation of controlled circulation boiler and natural circulation boiler start up behavior. Energy Conversion and Management, 46:533-549, 2005.

S. Lu, Dynamic modelling and simulation of power plant systems. In Proceedings of the Institution of Mechanical Engineers, Part A: Journal of Power and Energy, 213(1):722, 1999.

MATLAB: Documentation. The MathWorks Inc., 2016.

E. Majuri, Flow Distribution and Stability in a Two-phase Natural Circulation System. Master of Science Thesis, Tampere University of Technology, 2012.

A. Ordys, A.W. Pike, M.A. Johnson, R.M. Katebi and M.J. Grimble, Modelling and Simulation of Power Generation Plants. Springer-Verlag London Limited, 1st Edition, 1994

I.L. Pioro, R.B. Duffey and T.J. Dumouchel, Hydraulic resistance of fluids flowing in channels at supercritical pressures (survey). Nuclear Engineer and Design, 231:187197, 2004.

L.S. Tong and Y.S. Tang, Boiling Heat Transfer and Two-Phase Flow. 2nd edition, Taylor \& Francis, 1997.

T. Yli-Fossi, P. Köykkä and Y. Majanne, A Generalized Dynamic Water Side Model for a Once-Through Benson Boiler. In Preprints of the 18th IFAC World Congress: 7049-7054, Milano, Italy, 28 August-2 September 2011.

T. Yli-Fossi, P. Köykkä and Y. Majanne, A Tuning Tool for Gas Side Heat Transfer Coefficients of a Boiler Model. In Proceedings of the 8th IFAC Power Plant and Power System Control Symposium: 180-185, Toulouse, France, 25 September 2012.

R. Åman, Methods and Models for Accelerating Dynamic Simulation of Fluid Power Circuits. Dissertation, Lappeenranta University of Technology, 2011.

K.J. Åström and R.D. Bell, Drum-boiler dynamics. Automatica 36:363-378, 2000. 